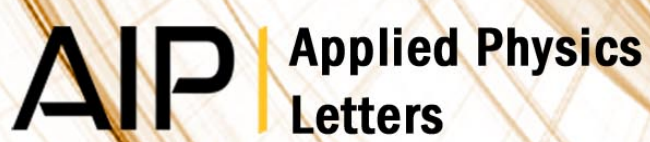

\section{Minority current distribution in InGaAs/GaAs transistor-vertical-cavity surface-emitting laser}

Y. Xiang, X. Yu, J. Berggren, T. Zabel, M. Hammar et al.

Citation: Appl. Phys. Lett. 102, 191101 (2013); doi: 10.1063/1.4803175

View online: http://dx.doi.org/10.1063/1.4803175

View Table of Contents: http://apl.aip.org/resource/1/APPLAB/v102/i19

Published by the American Institute of Physics.

Additional information on Appl. Phys. Lett.

Journal Homepage: http://apl.aip.org/

Journal Information: http://apl.aip.org/about/about_the_journal

Top downloads: http://apl.aip.org/features/most_downloaded

Information for Authors: http://apl.aip.org/authors

\section{ADVERTISEMENT}

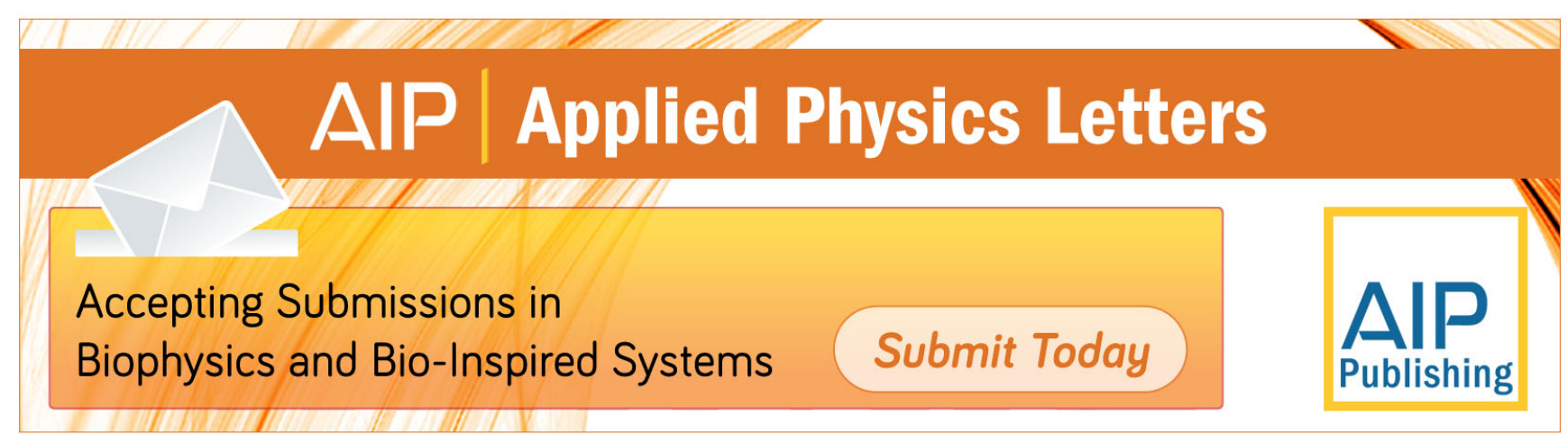




\title{
Minority current distribution in InGaAs/GaAs transistor-vertical-cavity surface-emitting laser
}

\author{
Y. Xiang, ${ }^{1, a)}$ X. Yu, ${ }^{1}$ J. Berggren, ${ }^{1}$ T. Zabel, ${ }^{1}$ M. Hammar, ${ }^{1}$ and M. N. Akram ${ }^{2}$ \\ ${ }^{1}$ KTH Royal Institute of Technology, School of Information and Communication Technology, Electrum 229, \\ S-164 40 Kista, Sweden \\ ${ }^{2}$ University College VestFold, Institute of Micro Nano Systems Technology, N-3103 Tønsberg, Norway
}

(Received 9 February 2013; accepted 12 April 2013; published online 13 May 2013)

\begin{abstract}
We compare experimental data with three-dimensional numerical calculations of the local minority current in an InGaAs/GaAs transistor vertical-cavity surface-emitting laser at different bias levels. It is demonstrated that lateral potential variations within the device greatly affect the transistor operating conditions. As a result, it locally operates in the active mode in the center of the device, allowing for efficient stimulated recombination, while it globally operates in the saturation regime as reflected by the measured current-voltage characteristics. This allows for excellent laser performance, including $\mathrm{mW}$-range output power, sub-mA threshold base current, and continuous-wave operation well above room temperature. (C) 2013 AIP Publishing LLC [http://dx.doi.org/10.1063/1.4803175]
\end{abstract}

The increasing demand for broadband capacity at all levels of optical communication networks has resulted in the investigation of new device concepts for increased modulation speeds. One such invention regards the so-called transistor-laser in which a heterojunction bipolar transistor (HBT) is monolithically integrated in a semiconductor laser. ${ }^{1,2}$ In this scheme it is possible to benefit simultaneously from the high efficiency and modulation capability of a semiconductor laser and the superior switching speed of an HBT. Since their introduction, transistor-lasers have attracted significant interest, and up to now devices based on many different material systems have been presented. ${ }^{3-5}$ A general observation from these studies is the signature of a negative differential current gain at the onset of stimulated recombination. However, because of the three-dimensional device nature this might be obscured due to local variations in the potential distribution inside the device. This is especially important in transistor vertical-cavity surface emitting lasers $(T-V C S E L s)^{6-8}$ that require special confinement schemes for efficient carrier injection. In our recent study of GaAs-based pnp-type $980-\mathrm{nm}$ T-VCSELs, ${ }^{8}$ we demonstrated that it is possible to get efficient lasing even far beyond transistor saturation. This was argued to be due to spatial potential variations within the device and the simultaneous occurrences of active and saturation modes at different positions. ${ }^{8}$

Here, we analyze the performance of $\mathrm{InGaAs} / \mathrm{GaAs}$ T-VCSELs by comparing experimental data with full threedimensional numerical simulations taking optical, electrical, and thermal effects into account. These results demonstrate that it is possible to have a device that locally works as a T-VCSEL while globally being in the transistor saturation regime.

The simulations were conducted using a commercially available software package, providing a full three-dimensional and self-consistent analysis based on the finite-element method for the optical mode distribution and the light-current-voltage characteristics, also including thermal effects. ${ }^{9}$ While the

\footnotetext{
${ }^{\text {a) }}$ Author to whom correspondence should be addressed. Electronic mail: yxiang@kth.se
}

actual devices are of square geometry, we here used a cylindrical model of the same active volume to save computation time. This simplification has been found to have minor influence on electrical characteristics and total optical power. More detailed information regarding the simulation tools and physical parameters of the material are reported elsewhere. ${ }^{10}$

The device was fabricated using metal-organic vaporphase epitaxy and consists of a pnp-HBT structure with a triple intrinsic InGaAs/GaAs quantum well (QW) active region embedded in the base. Figure 1 illustrates the schematics of the final device of which the details are presented elsewhere. ${ }^{8}$ From bottom to top the layer structure consists of an undoped $\mathrm{AlGaAs} / \mathrm{GaAs}$ distributed Bragg reflector (DBR) followed by a p-type GaAs subcollector and an intrinsic GaAs collector. The consecutive n-doped GaAs base region hosts the triple InGaAs/GaAs QW active region. The emitter consists of a p-type AlGaAs layer. Additional charge carrier confinement inside the emitter region is provided by an n-type current blocking layer with a lateral dimension of $10 \mu \mathrm{m}$ which was developed from our previous GaAs-based VCSELs for $1.3 \mu \mathrm{m}$ regime. ${ }^{11}$ This results in the formation of an aperture of $10 \mu \mathrm{m}$ size. Finally the structure is capped with a $\mathrm{SiO}_{2} / \alpha$-Si dielectric DBR. For electrical access, AuZn and PdTiGe ohmic contacts have been evaporated on $p$ and n-type GaAs areas, respectively.

Electro-optical characterization of the three-terminal device was conducted in the common-emitter configuration. With this biasing scheme, holes are injected from the emitter into the base region. As minority carriers, the holes inside the base region diffuse towards the collector and partially get trapped by the QWs allowing for efficient radiative recombination. In Fig. 2(a) we present the room temperature electroluminescence at a constant collector-emitter voltage $\left(\mathrm{V}_{\mathrm{CE}}\right)$ of $1.4 \mathrm{~V}$ for different base currents $\left(\mathrm{I}_{\mathrm{B}}\right)$. At low $\mathrm{I}_{\mathrm{B}}=0.7 \mathrm{~mA}$ a broad electroluminescence spectrum is observed as stemming from the QWs due to spontaneous recombination of injected charge carriers. With increasing current injection we find that the peak intensity strongly increases whereas the peak linewidth decreases. This is a strong indication of a transition from spontaneous to stimulated emission. This 


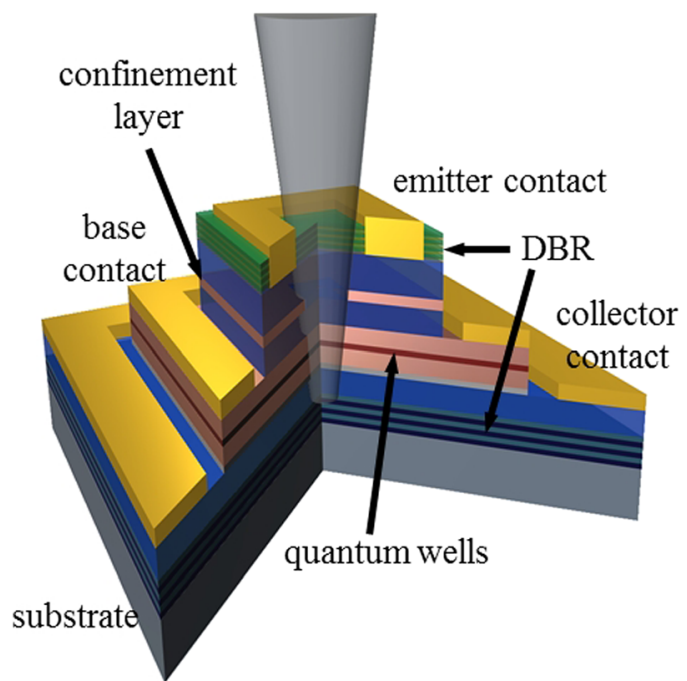

FIG. 1. Schematic illustration of the fabricated T-VCSEL. From bottom to top, the structure consists of the substrate (grey), the bottom DBR (black), the subcollector and collector (blue). Thereafter the n-doped base (pink) and QWs (red) are deposited followed by the p-doped emitter (blue) embedding an n-doped confinement layer (pink). The structure is capped with a $\mathrm{SiO}_{2} /$ $\alpha$-Si dielectric top DBR.

behavior is summarized in Fig. 2(b) where we show the measured optical output power as a function of $\mathrm{I}_{\mathrm{B}}$ at different $\mathrm{V}_{\mathrm{CE}}$. We find that the threshold current for the onset of stimulated emission is $0.75 \mathrm{~mA}$ as manifested by the kink in the output power. With stimulated emission becoming dominant, the output power increases linearly with rising $I_{B}$ until it gradually saturates. ${ }^{12}$ Apparently the magnitude of the saturated power depends on $\mathrm{V}_{\mathrm{CE}}$ and occurs at lower $\mathrm{I}_{\mathrm{B}}$ with lower $\mathrm{V}_{\mathrm{CE}}$. In the case of voltage control (shown elsewhere of Ref. 8), the output power also exhibits a threshold with a subsequent linear increase. It also shows saturation when the base-collector junction starts to be forward biased. ${ }^{7}$

In order to understand the electrical behavior of the transistor in the presence of spontaneous and stimulated emission, the experimental (solid line) collector current $\left(\mathrm{I}_{\mathrm{C}}\right)$ (blue) and base voltage (red) as function of $\mathrm{I}_{\mathrm{B}}$ at a constant

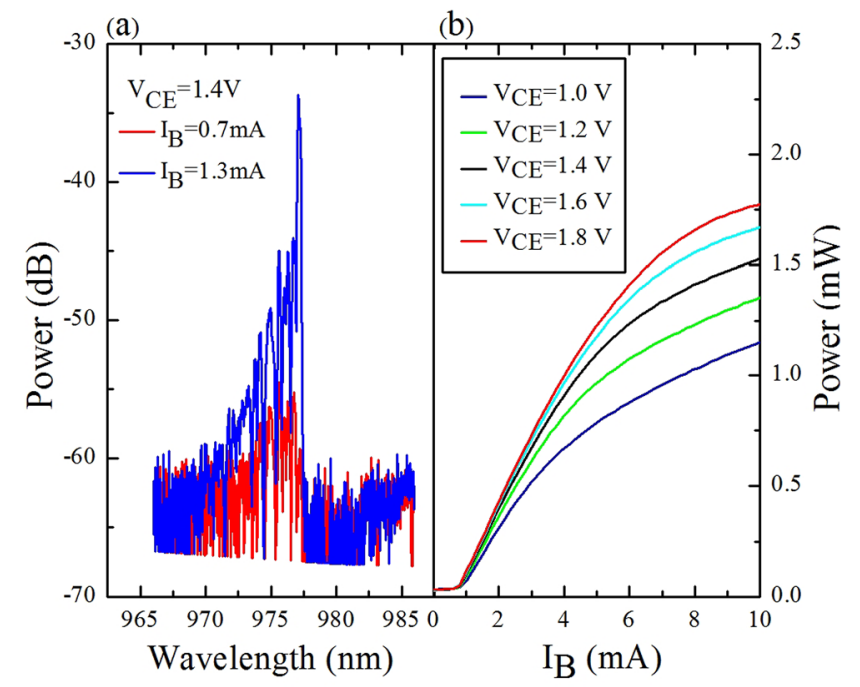

FIG. 2. Room temperature measurements of (a) optical spectrum at different base currents, and (b) continuous-wave optical power as function of $\mathrm{I}_{\mathrm{B}}$ for various $\mathrm{V}_{\mathrm{CE}}$.
$\mathrm{V}_{\mathrm{CE}}=3 \mathrm{~V}$ are illustrated in Fig. 3. The inset shows a zoomin for $\mathrm{I}_{\mathrm{B}}$ lower than $1 \mathrm{~mA}$. In addition we have included the calculated characteristics (dashed lines), which show good agreement with the experimental results. For $\mathrm{I}_{\mathrm{B}}=0-0.4 \mathrm{~mA}$, $\mathrm{I}_{\mathrm{C}}$ shows a superlinear increase with a maximum differential current gain $\left(\beta=\Delta \mathrm{I}_{\mathrm{C}} / \Delta \mathrm{I}_{\mathrm{B}}\right)$ of 26 . For $\mathrm{I}_{\mathrm{B}}>0.4 \mathrm{~mA}$ the differential current gain turns negative and $\mathrm{I}_{\mathrm{C}}$ decreases. This behavior is accompanied by a steep increase of the baseemitter voltage up to $\mathrm{I}_{\mathrm{B}}=0.4 \mathrm{~mA}$ and a subsequently decreasing slope. For $\mathrm{I}_{\mathrm{B}}>18 \mathrm{~mA}, \mathrm{I}_{\mathrm{C}}$ approaches $0 \mathrm{~mA}$ and eventually turns negative.

Contrary to what is usually observed, we note an absence of the reduction in differential current gain at lasing threshold $\left(\mathrm{I}_{\mathrm{B}}=0.75 \mathrm{~mA}\right)^{6,12,13}$ Instead, we find a pronounced gain compression below threshold as indicated by the drop in $\mathrm{I}_{\mathrm{C}}$ at $\mathrm{I}_{\mathrm{B}}=0.4 \mathrm{~mA}$. To account for this behavior we have simulated the current and potential distribution inside the T-VCSEL for different levels of $\mathrm{I}_{\mathrm{B}}$. In Fig. 4 we show cross-sectional color plots of the hole current densities at $\mathrm{I}_{\mathrm{B}}=0.5 \mathrm{~mA}$ (a), $\mathrm{I}_{\mathrm{B}}=1 \mathrm{~mA}(\mathrm{~b})$, and $\mathrm{I}_{\mathrm{B}}=20 \mathrm{~mA}$ (c), respectively. The plots also include equipotential lines highlighted with additional labels in black. Finally, dark grey arrows indicate the direction of injected current.

Independently of $\mathrm{I}_{\mathrm{B}}$ we find a charge crowding effect adjacent to the edge of the n-doped confinement layer inside the emitter. Figure 4(a) illustrates the current in standard transistor on-state, where holes injected from the emitter into the base diffuse towards the collector. Inside the collector the applied potential then results in a drift current $\left(\mathrm{I}_{\mathrm{C}}\right)$ towards the contact. Furthermore, the confinement provided by the QWs can trap holes which then eventually contribute to $\mathrm{I}_{\mathrm{B}}$ by means of radiative recombination.

A similar situation can be found for $\mathrm{I}_{\mathrm{B}}=1 \mathrm{~mA}$ (b) and for $20 \mathrm{~mA}$ (c), respectively. However, we find that the voltage applied at the collector contact is not sufficient to maintain a potential drop across the whole collector. With increasing base current, the position, where most holes are injected into the collector volume, shifts closer to the collector. Already at a base current of $1 \mathrm{~mA}$, which is slightly above lasing

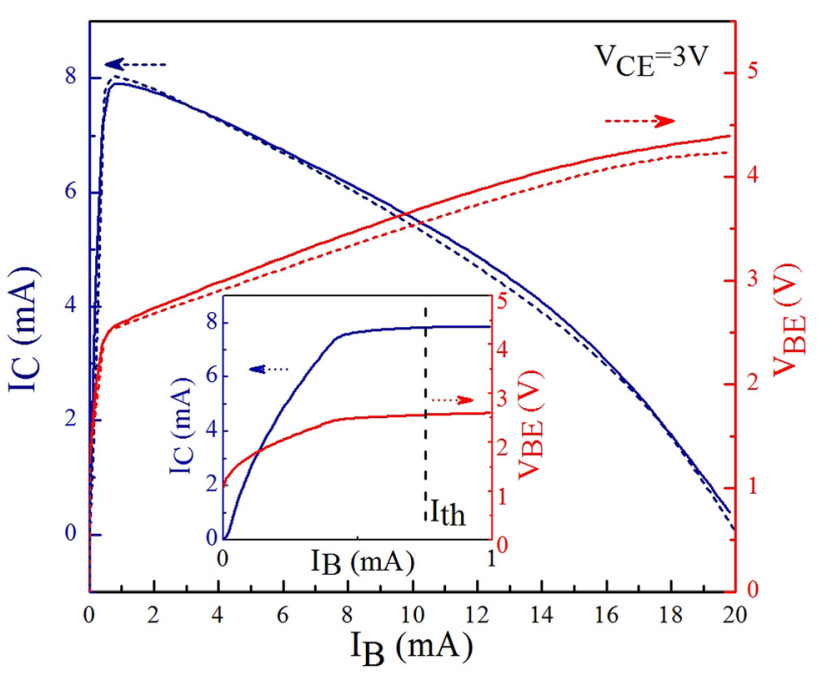

FIG. 3. Simulated (dashed line) versus measured (solid line) I-V characteristics of the T-VCSEL. The inset shows the same experimental results below $\mathrm{I}_{\mathrm{B}}=1 \mathrm{~mA}$. 


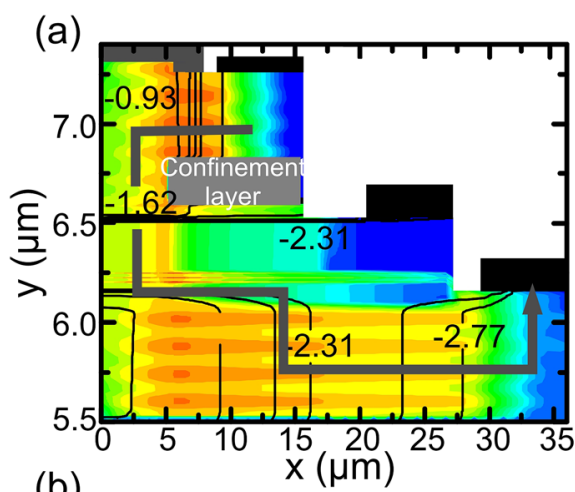

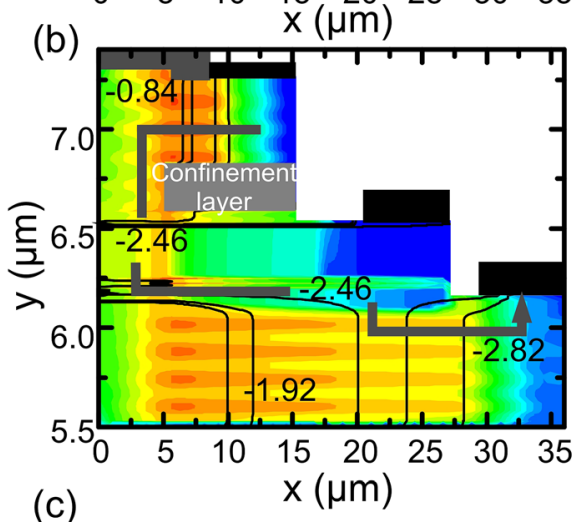

$\log \left(I_{\text {hole }}\right)$ $\left(\mathrm{A} / \mathrm{cm}^{2}\right)$

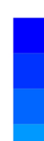

$-1.000$ $-0.670$ $-0.340$ $-0.010$ 0.320 0.650 0.980 1.310 1.640 1.970 2.300 2.630 2.960 3.290 3.620 3.950 4.280 4.610 4.940 5.270

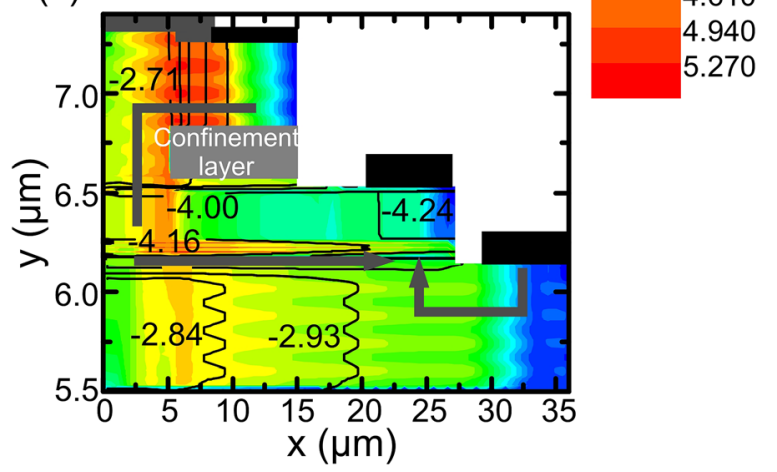

FIG. 4. Calculated cross-sectional contour plots of the hole current density at different biasing conditions: (a) $\mathrm{I}_{\mathrm{B}}=0.5 \mathrm{~mA}$, (b) $\mathrm{I}_{\mathrm{B}}=1 \mathrm{~mA}$, and (c) $\mathrm{I}_{\mathrm{B}}=20 \mathrm{~mA}$. Equipotential lines are indicated in black, while the grey arrows illustrate the directions of the current flow. The confinement layer is highlighted in dark grey. The black regions indicate the contact. The emitter contact potential is fixed at $0 \mathrm{~V}$ while the collector potential is at $-3 \mathrm{~V}$.

threshold, this current path is almost blocked. In addition, a high potential is built-up within and close to the QWs resulting in a redistribution of the current path in lateral direction of the base. Even more, for $\mathrm{I}_{\mathrm{B}}=20 \mathrm{~mA}$ charge carriers flow from the collector into the base close to the contacts, resembling transistor saturation. Despite this, in the center of the device some charge carriers diffuse into the collector resembling transistor on-state.

In conclusion, we find that for high $\mathrm{I}_{\mathrm{B}}$ the transistor is in its on-state close to the center of the device whereas it is in saturation close to the contact. This behavior is a direct result from the potential which is located inside the QWs with increasing charge carrier density partially closing the current path towards the collector contact. It screens the potential drop within the collector resulting in lower drift current, and it is higher than the applied potential at the collector contact allowing for back injection and lateral current flow. It is such a built-in potential that reduces $\mathrm{I}_{\mathrm{C}}$ and the differential current gain, which can be observed in Fig. 3 at the kink close to $\mathrm{I}_{\mathrm{B}}=0.4 \mathrm{~mA}$.

We want to highlight that in the center of the device, the base-collector junction is still reverse biased and charge carriers are swept from the base into the collector. Hence, the device locally acts as a T-VCSEL albeit the global I-V characteristics do not resemble this behavior. This shows that it is not necessary for a transistor laser to show a drop in current gain at lasing threshold.

In summary, a GaAs-based $980 \mathrm{~nm}$ transistor VCSEL was fabricated and measured at room temperature. An unusual $\mathrm{I}_{\mathrm{C}}-\mathrm{I}_{\mathrm{B}}$ behavior with a negative differential current gain below lasing threshold has been observed. Using realistic simulations we conclude that this is a result of an inhomogeneous local potential distribution in the collector region. Our results show that upon an increasing base current the base collector junction can, locally, start to be in saturation close to the collector contact. This prevents charge carriers from drifting laterally towards the collector contact and, hence, efficiently reduces the $\mathrm{I}_{\mathrm{C}}$. At the same time the whole device still locally acts as a transistor in forward bias close to the optically active center of the device. Preliminary calculations suggest that an optimized device design, in particular increased base doping level and decreased base width, would allow for a reduced influence of lateral potential variations.

We thank Wei Shi and Lukas Chrostowski at the University of British Columbia for their help in setting up the numerical simulations. We also acknowledge the financial support by the Swedish Research Council (Grant No. 2010-4386).

${ }^{1}$ M. Feng, N. Holonyak, Jr., and R. Chan, Appl. Phys. Lett. 84, 1952 (2004).

${ }^{2}$ M. Feng, N. Holonyak, Jr., G. Walter, and R. Chan, Appl. Phys. Lett. 87, 131103 (2005).

${ }^{3}$ M. Shirao, T. Sato, Y. Takino, N. Sato, N. Nishiyama, and S. Arai, Appl. Phys. Express 4, 072101 (2011).

${ }^{4}$ Y. Huang, J. Ryou, R. D. Dupuis, F. Dixon, M. Feng, and N. Holonyak, Jr., J. Appl. Phys. 109, 063106 (2011).

${ }^{5}$ Z. Duan, W. Shi, L. Chrostowski, X. Huang, N. Zhou, and G. Chai, Opt. Express 18(2), 1501-1509 (2010).

${ }^{6}$ M. K. Wu, M. Feng, and N. Holonyak, IEEE Photonics Technol. Lett. 24, 1346 (2012).

${ }^{7}$ M. K. Wu, M. Feng, and N. Holonyak, Appl. Phys. Lett. 101, 081102 (2012).

${ }^{8}$ X. Yu, Y. Xiang, J. Berggren, M. Hammar, N. Akram, W. Shi, and L. Chrostowski, Electron. Lett. 49(3), 208-210 (2013).

${ }^{9}$ PICs3D Crosslight Device Simulation Software, Crosslight Software, Inc.

${ }^{10}$ W. Shi, B. Faraji, M. Greenberg, J. Berggren, Y. Xiang, M. Hammar, M. Lestrade, Z. Li, Z. M. S. Li, and L. Chrostowski, Opt. Quantum Electron. 42, 659-666 (2011).

${ }^{11}$ R. M. von Würtemberg, X. Yu, J. Berggren, and M. Hammar, IET Optoelectron. 3, 112 (2009).

${ }^{12}$ W. Shi, L. Chrostowski, and B. Faraji, IEEE Photonics Technol. Lett. 20, 2141 (2008).

${ }^{13}$ G. Walter, N. Holonyak, M. Feng, and R. Chan, Appl. Phys. Lett. 85, 4768 (2004). 